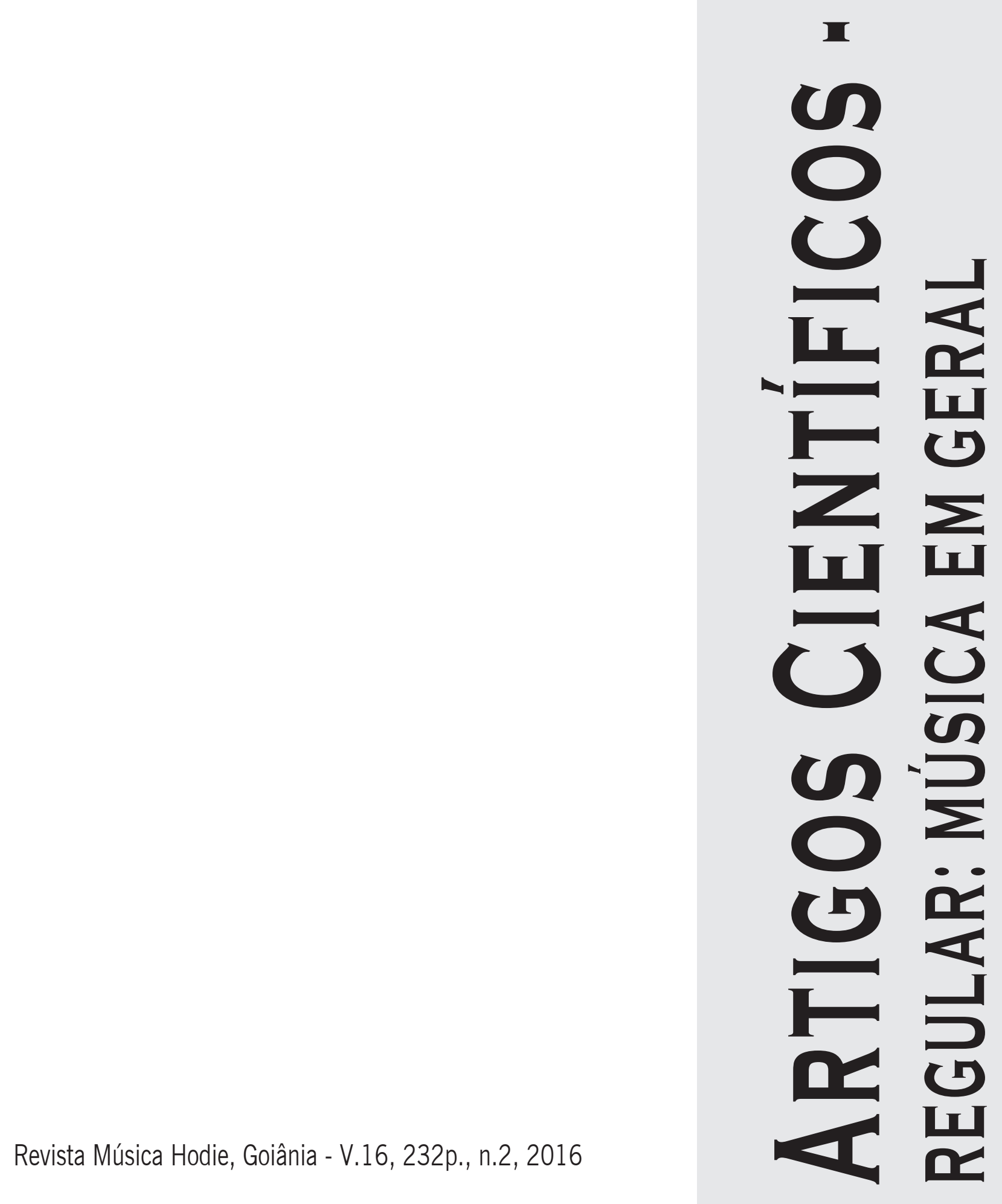




\title{
O formante do cantor e os ajustes laríngeos e supralaríngeos em cantores barítonos: uma investigação acústica e fibronasolaringoscopica
}

\author{
Cristina de Souza Gusmão (Universidade Federal de Minas Gerais, Belo Horizonte, MG, Brasil) \\ tina_gusmao@yahoo.com.br \\ Mônica Pedrosa de Pádua (Universidade Federal de Minas Gerais, Belo Horizonte, MG, Brasil) \\ monicapedrosa1@gmail.com \\ Mariana Oliveira Maia (Universidade Federal de Minas Gerais, Belo Horizonte, MG, Brasil) \\ marianamaiaotorrino@hotmail.com
}

\begin{abstract}
Resumo: Este trabalho apresenta resultados de pesquisa com foco no Formante do Cantor. Nosso objetivo principal foi identificar tipos de ajustes laríngeos e supralaríngeos ocorridos durante o aparecimento desse fenômeno numa emissão de voz cantada. Doze (12) barítonos foram avaliados por meio de aferições acústicas e de imagem pelo exame de Fibronasolaringoscopia. A gravação e a análise acústica foram feitas com os programas WaveSurfer e Praat. O principal ajuste encontrado foi o abaixamento da laringe. Outros recursos foram encontrados, alguns deles não citados na literatura como ideais, possivelmente associados a questões técnicas do canto, alterações estruturais do aparelho fonador e/ou a questões étnicas. O conhecimento desses ajustes poderá auxiliar cantores no desenvolvimento de sua técnica vocal.
\end{abstract}

Palavras-chave: Análise acústica da voz; Formante do cantor; Ajustes laríngeos; Técnica vocal; Pedagogia do canto lírico.

The singer's formant and laryngeal and supralaryngeal adjustments inbariton singers: an acoustic and fibronasolarincoscopic research

Abstract: This paper presents the results of a research focusing on the Singer's Formant. Our main goal was to identify types of laryngeal and supralaryngeal adjustments occurred during the appearance of this phenomenon during utterance of singing voice. Twelve baritones were evaluated through acoustic assessment and imaging in the fibronasolaringoscopy exam. The recordings and the acoustic analysis were made through WaveSurfer audio software and Praat program. All the baritones evaluated presented laryngeal lowering as the main capabilities for the Singer's Formant. Other adjustments were found, some not mentioned in the literature as ideal, possibly associated with technical aspects of singing, structural alterations of the vocal tract and/or ethnicity. Knowledge of these adjustments may help singers to develop their vocal technique.

Keywords: Acoustic voice analysis; The singer's formant; Laryngeal adjustments; Vocal technique; Pedagogy of classical singing.

El formante del cantante y ajustes laríngeos y supralaríngeos em cantantes barítonos: una investigación acústica y fibronasolaringoscopica

Resumen: Este artículo presenta los resultados de investigación que se centra en el Formante del Cantante. Nuestro principal objetivo fue identificar los tipos de ajustes laríngeos y supralaríngeos que se produjeran durante la aparición de este fenómeno en la voz cantada. Doce barítonos fueron evaluados mediante mediciones de sonido e imagen mediante el examen de fibronasolaryngoscopy. Grabación y análisis acústico se fueran realizadas con los programas de WaveSurfer y Praat. Se encontró que el ajuste principal era el descenso de la laringe. Se encontraron otros recursos, pero algunos no se mencionan en la literatura como ideales, posiblemente asociados con aspectos técnicos de canto, los cambios estructurales de las vías y/o etnia. El conocimiento de estos ajustes puede ayudar a cantantes para desarrollar su técnica vocal.

Palabras clave: Análisis acústico de la voz; Formante del cantante; Ajustes de la laringe; Técnica vocal; Pedagogía del canto clásico.

\section{Introdução}

O fenômeno da voz que faz com que ela sobressaia a uma orquestra é denominado por Sundberg (1974, 2015), Appleman (1986) e Vieira (2004) como Formante do Cantor, tema deste estudo. O Formante do Cantor pode ser definido pela amplificação sonora das frequências de 2 a $4 \mathrm{KHz}$ aproximadamente, do som fundamental produzido na laringe. 
A fonte do som vocal, constituída pela vibração das pregas vocais na laringe, produz um som composto de uma rica série de frequências e o trato vocal amplifica e filtra as frequências compatíveis com o seu formato e com a sua acústica (TITZE, 1994, p. 237). “O trato vocal é o nosso filtro sonoro, constituído por laringe, faringe, boca, cavidades nasais e paranasais. São verdadeiras cavidades de ressonância da voz" (ANDRADE e SILVA e DUPRAT, 2010, p. 771).

Alguns dos harmônicos do som fundamental produzido pelas pregas vocais decaem próximo aos picos de ressonância do trato vocal e o percorrem sem serem reforçados. Outros harmônicos são mais fortemente ressaltados pelo filtro (trato vocal) e são denominados formantes. Geralmente, o trato vocal possui quatro ou cinco formantes mais relevantes (STEVENS e HOUSE, 1961; 35).

Segundo BEHLAU (2001), os formantes, na maioria das vezes, são expressos pelo seu valor médio em Hertz (Hz), ou ciclos por segundo, e designados por F1, F2, F3, [...] Fn, progressivamente. A qualidade que distingue as vogais pode ser atribuída a variações relativas das duas primeiras frequências dos formantes F1 e F2, causadas pelas modificações das estruturas orais articuladoras do som, como a língua e os lábios. Já o terceiro, o quarto e o quinto formantes não têm a mesma variação, sendo então considerados estáveis (MASTER, 2006). Assim sendo, são responsáveis pelo timbre pessoal, ou seja, pela qualidade e brilho da voz (BEHLAU, 2001). Considerados de grande importância para a voz cantada, esses formantes superiores (junção de F3, F4 e F5) são denominados Formante do Cantor (SUNDBERG, 1991; CORDEIRO, PINHO e CAMARGO, 2007 e REID, et al, 2007).

A literatura relata que, na voz cantada, o Formante do Cantor é encontrado em vozes graves. No registro masculino ele aparece nas vozes classificadas como baixo, barítono, tenor e, segundo Cruz (2006), também na voz do contratenor. Na classificação feminina é encontrado na voz de contralto. As frequências do Formante do Cantor já estão presentes na tessitura vocal de um soprano, pois este ocorre ao redor de $3.000 \mathrm{~Hz}$ (TITZE, 1994, 2013). Por isso, pode-se afirmar que sopranos já têm o Formante do Cantor. Esse fenômeno é encontrado em vozes de cantores e atores treinados. Vozes não treinadas não apresentam boa definição desses formantes superiores (STONE et all, 1999; CLEVELAND et all, 2001; BELLE, 2006, MASTER, 2006; BJORNER, 2008; LEINO et all, 2010 e FERGUSON et all, 2010).

Alguns ajustes laríngeos e faríngeos são abordados como facilitadores para o fenômeno do Formante do Cantor, tais como: o alongamento do tubo laringofaríngeo (CORDEIRO et al apud ANDRADE e SILVA e DUPRAT, 2010), promovido pelo abaixamento da laringe e pela elevação do véu palatino; os movimentos da língua e a verticalização dos movimentos da mandíbula; o alargamento da cavidade faríngea; o alongamento do tubo da faringe e a constrição ariepiglótica (aproximação da cartilagem da epiglote com as cartilagens aritenóideas) (BEHLAU, 2001). O abaixamento da laringe é citado como um dos principais ajustes para favorecer o Formante do Cantor (SUNDBERG, 1974,1977,2015; CRUZ, 2006; BEHLAU, 2001).

A realização de ajustes no trato vocal que atenuem e amplifiquem determinadas frequências que irão favorecer o Formante do Cantor é feita, muitas vezes, de forma inconsciente por muitos cantores, principalmente porque o fenômeno é pouco comentado pedagogicamente, sendo até mesmo desconhecido por cantores que participaram desta pesquisa. Nesse contexto, o objetivo principal deste trabalho foi averiguar os tipos de ajustes laríngeos e supralaríngeos realizados por cantores barítonos, que resultaram na presença ou ausência do Formante do Cantor durante o canto.

Na pesquisa realizada, tornou-se crucial entender quais ajustes técnicos são necessários para a emissão de um som vocal com qualidade adequada ao contexto operístico, com sonoridade que atenda à necessidade do canto atual, visto que as vozes necessitam atingir 
as últimas fileiras dos grandes teatros. Acreditamos que o conhecimento desses ajustes poderá auxiliar cantores no desenvolvimento de sua técnica vocal.

\section{Materiais e método}

Este trabalho apresenta resultados da pesquisa de mestrado da primeira autora, aprovada pelo Comitê de Ética em Pesquisa da Universidade Federal de Minas Gerais (UFMG). Todos os participantes admitidos no estudo assinaram o Termo de Consentimento Livre e Esclarecido a fim de que tivessem conhecimento dos objetivos do estudo, bem como da metodologia utilizada. A pesquisa contou com a colaboração de 12 (doze) cantores líricos do sexo masculino, classificados como barítonos. Todos eles trabalhavam como cantores e possuíam experiência de no mínimo 3 (três) anos na prática do canto erudito.

Os participantes receberam a ária Non Più Andrai, da ópera As Bodas de Fígaro, do compositor W.A Mozart, para cantarem durante os procedimentos de mensuração dos formantes. Todos foram orientados a praticar um aquecimento vocal de livre escolha antes da gravação da ária.

Os procedimentos utilizados nesta pesquisa foram o exame de Fibronasolaringoscopia, para captação da imagem laríngea, e a gravação do áudio da voz, ambos realizados na clínica de Otorrinolaringologia e Fonoaudiologia Amélio Maia, em BH - MG. O exame foi realizado por uma médica Otorrinolaringologista e a gravação do áudio pela pesquisadora. Todos os sujeitos receberam um anestésico local (Decadron $10 \mathrm{ml}$ ), dois jatos em cada narina, 2 (dois) minutos antes do exame, para diminuir o desconforto durante o mesmo.

Enquanto o sujeito da pesquisa fazia o exame de Fibronasolaringoscopia, foi realizada, simultaneamente, a gravação do áudio utilizando o programa WaveSurfer. Durante a gravação, o sujeito ficou em pé diante de um pedestal que foi ajustado a sua altura, no qual havia um microfone que se conectava diretamente a uma placa de áudio, que transmitia o sinal para um computador. Para garantir que todos os cantores cantassem no mesmo tom e no mesmo andamento, foi disponibilizado um áudio com a gravação do acompanhamento do trecho, executado por um pianista. Para ouvir o acompanhamento da ária, os cantores utilizaram o fone de ouvido conectado a um computador.

No exame de Fibronasolaringoscopia, utilizou-se um aparelho Naso-faringo-laringoscópio flexível, modelo ENT -30PIV, marca MACHIDA, conectado a uma câmera Control Unit Tochiba, modelo K-CU43A focus loock SOAKABLE, lente IKM43H67. Esse conjunto foi conectado a uma fonte de luz HL 2250 Komlux.

Para a gravação do áudio, foram utilizados um microfone Shure SM58, conectado a um placa de áudio M-AUDIO Fast Track, ligado diretamente a um computador Toshiba, para a captação da voz do cantor, e um fone de ouvido Fhilips SHM I 900, utilizado para ouvir o trecho gravado. Para a captação do áudio, foi utilizado o programa WaveSurfer versão 1.8.5/0511011429.

Antes do início da gravação do áudio, foi solicitado aos cantores que cantassem o trecho da ária interpretando o personagem, ou seja, que dessem vida ao personagem como se estivessem num contexto de performance.

Após a coleta dos dados, a gravação do áudio foi copiada para o programa de análise acústica Praat. Esse programa nos oferece uma Espectrografia de Banda Larga (EBL), informando as faixas de frequências dos formantes do som vocal. Nos cantores que apresentaram esse fenômeno, identificamos e analisamos, por meio do exame de laringe, o tipo de ajuste laríngeo e supralaríngeo realizado no momento da emissão vocal. 
Para a análise acústica, foram avaliados os compassos $9^{\circ}, 10^{\circ}$ e $11^{\circ}$ da ária. A escolha por esses compassos se deu pelo fato dos cantores estarem mais familiarizados com o trecho, já que era a segunda vez que o mesmo se repetia. Além disso, nesse trecho ocorre uma progressão melódica ascendente culminando na nota mais aguda da ária, em dinâmica forte, o que leva os cantores a cantarem com mais energia. Esses dois fatores possibilitaram aos cantores uma emissão sonora, no trecho em questão, mais desenvolta, segura e intensa. Como nosso objetivo foi averiguar os ajustes laríngeos e supralarígeos no Formante do Cantor, optamos por um trecho cujo resultado sonoro nos permitisse maior facilidade de aferição. $\mathrm{O}$ trecho avaliado pode ser visualizado na Figura 1.

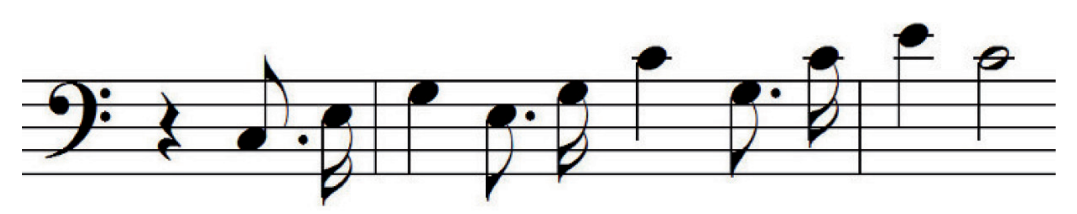

del - le bel-le tur-ban-do_il ri - po-so,
Figura 1: Trecho da ária Non Più Andrai avaliado na análise acústica. Fonte: MOZART, 1986.

Para a caracterização da Espectrografia de Banda Larga (EBL), foram avaliados os seguintes aspectos: identificação das frequências de F1, F2, F3 e F4 e verificação da presença ou ausência do Formante do Cantor.

No exame de Fibronasolaringoscopia foram avaliados os seguintes parâmetros: 1 . Na laringe: o abaixamento de laringe e a constrição ariepiglótica; 2. Na faringe: o alargamento da faringe ou sua constrição lateral. Foi incluído também o item base de língua posteriorizada, já que foi encontrado em alguns barítonos.

\section{Resultados}

A Espectografia de Banda Larga realizada a partir das gravações das vozes dos barítonos gerou os gráficos que serão apresentados a seguir (Figuras 2 a 13). Os gráficos apresentam a frequência no eixo vertical e o tempo no eixo horizontal. As linhas horizontais, de baixo para cima, representam as faixas de frequência do primeiro, segundo, terceiro e quarto formantes, identificados como F1, F2, F3 e F4. A intensidade da emissão é representada pelo grau de escurecimento das linhas horizontais.

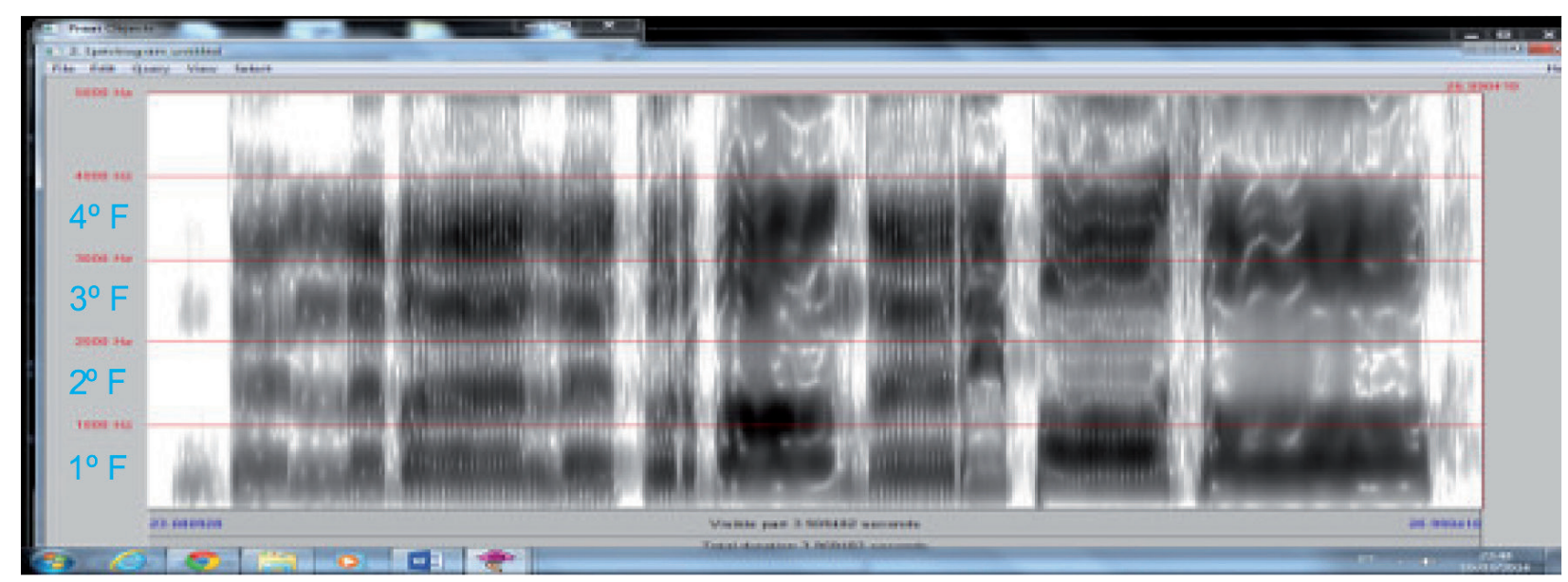

Figura 2: Barítono 1 - Espectografia de banda larga. Fonte: Análise acústica retirada do Programa Praat. 


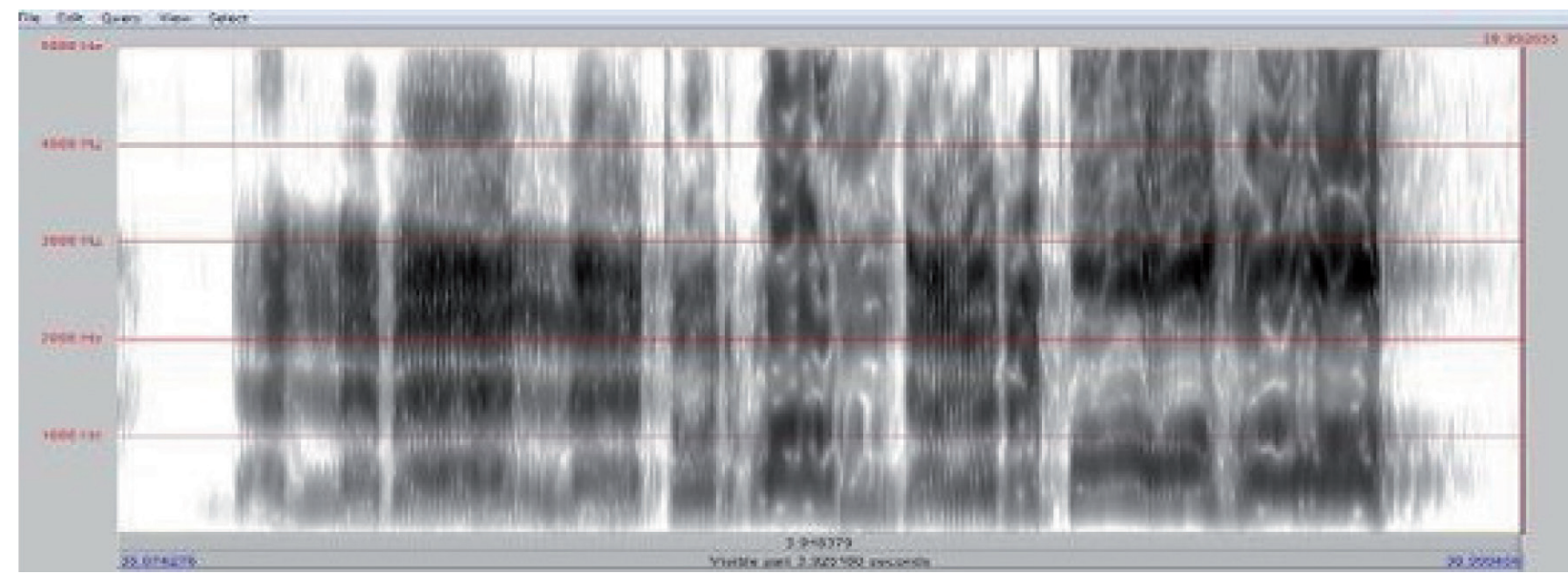

Figura 3: Barítono 2 - Espectografia de banda larga. Fonte: Análise acústica retirada do Programa Praat.

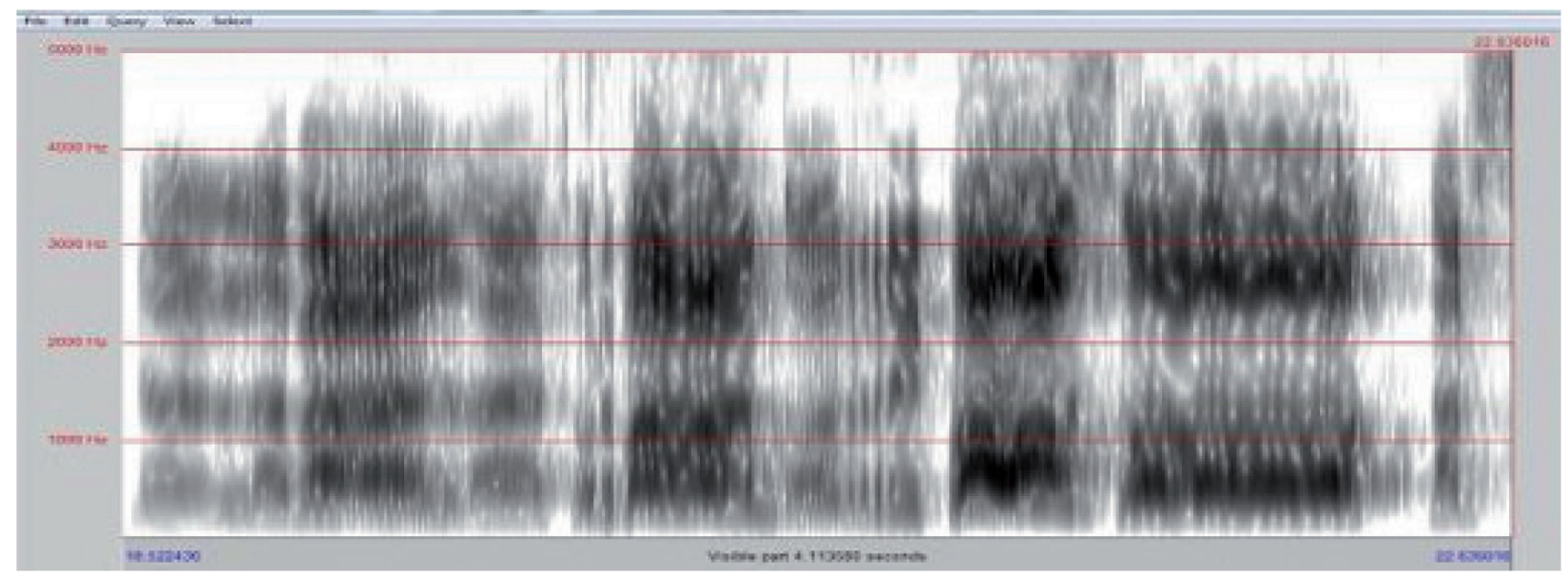

Figura 4: Barítono 3 - Espectografia de banda larga. Fonte: Análise acústica retirada do Programa Praat.

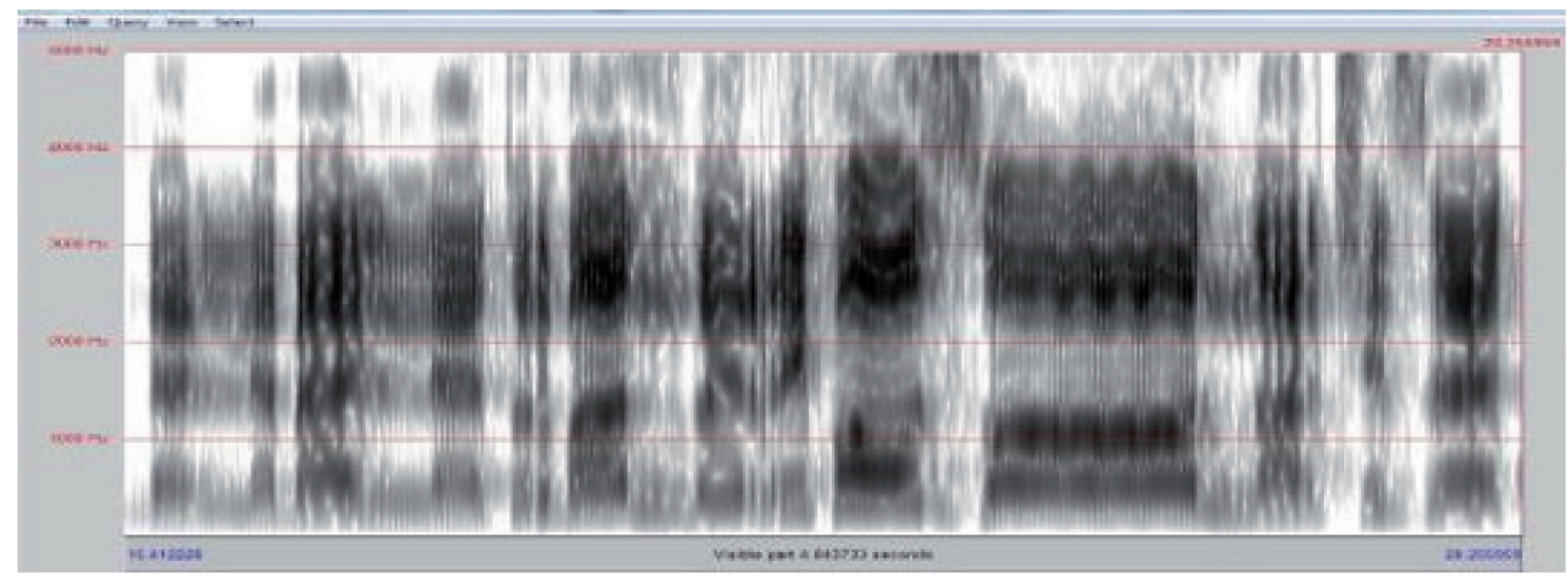

Figura 5: Barítono 4 - Espectografia de banda larga. Fonte: Análise acústica retirada do Programa Praat. 


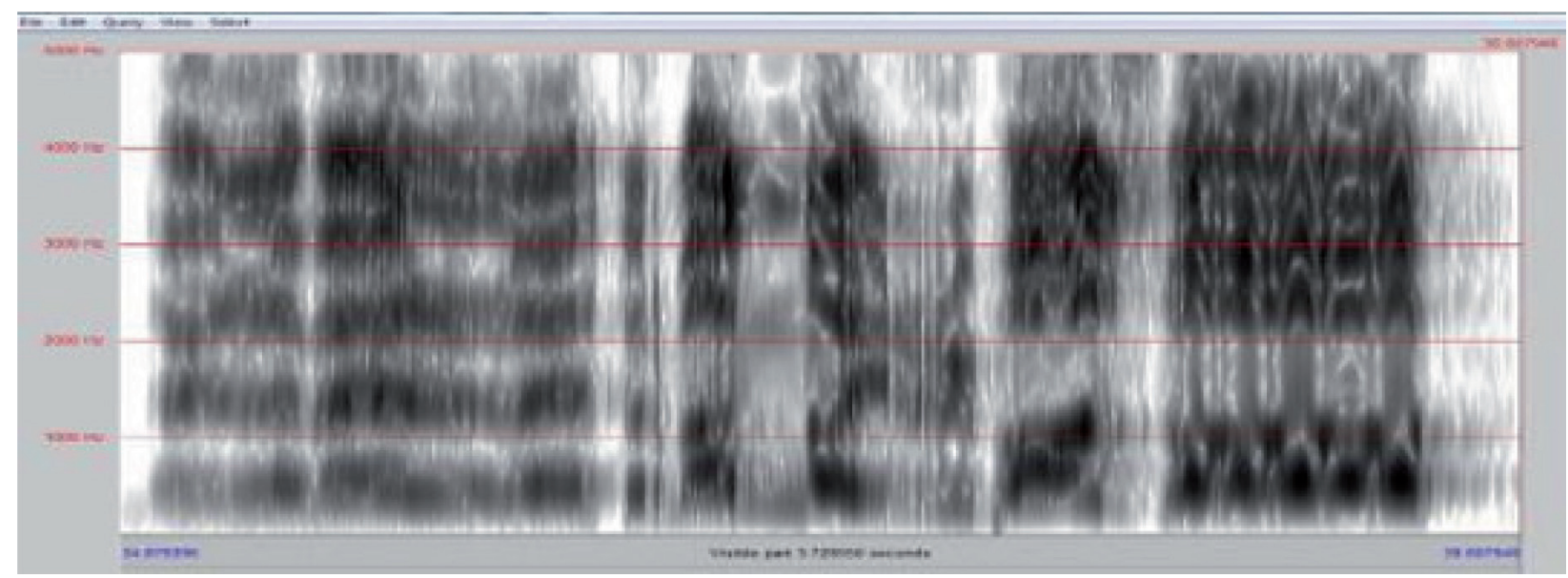

Figura 6: Barítono 5 - Espectografia de banda larga. Fonte: Análise acústica retirada do Programa Praat.

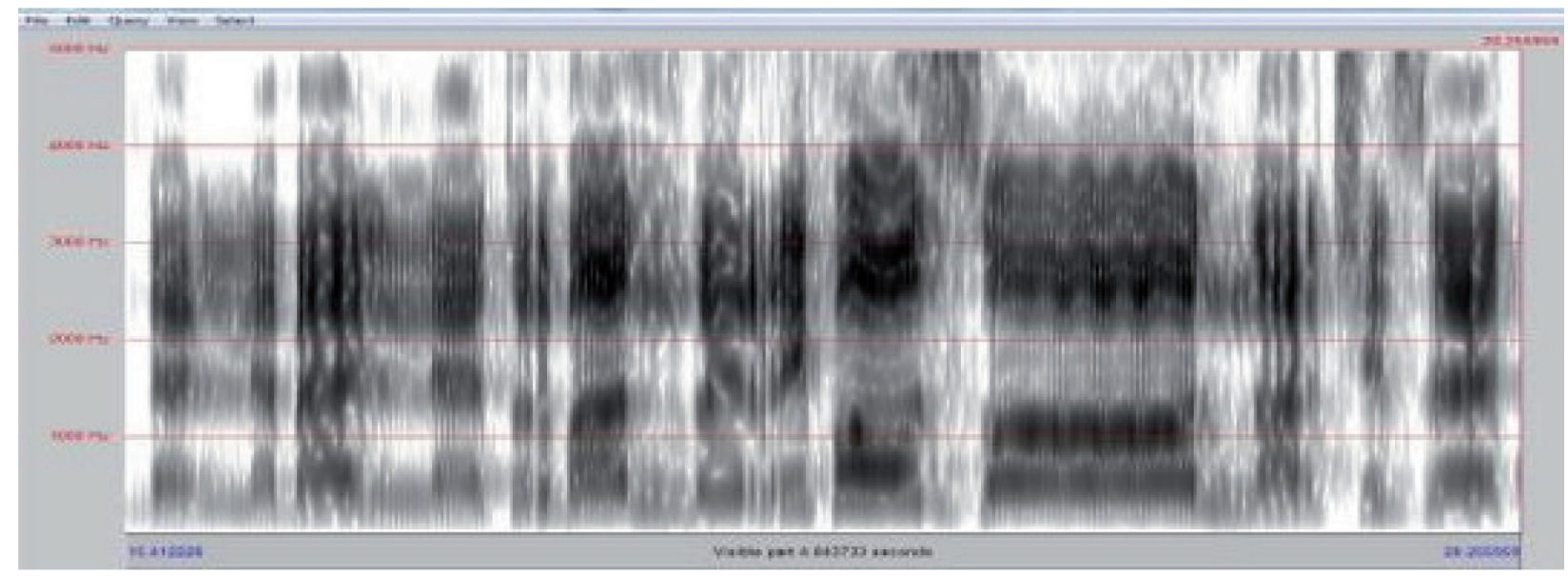

Figura 7: Barítono 6 - Espectografia de banda larga. Fonte: Análise acústica retirada do Programa Praat.

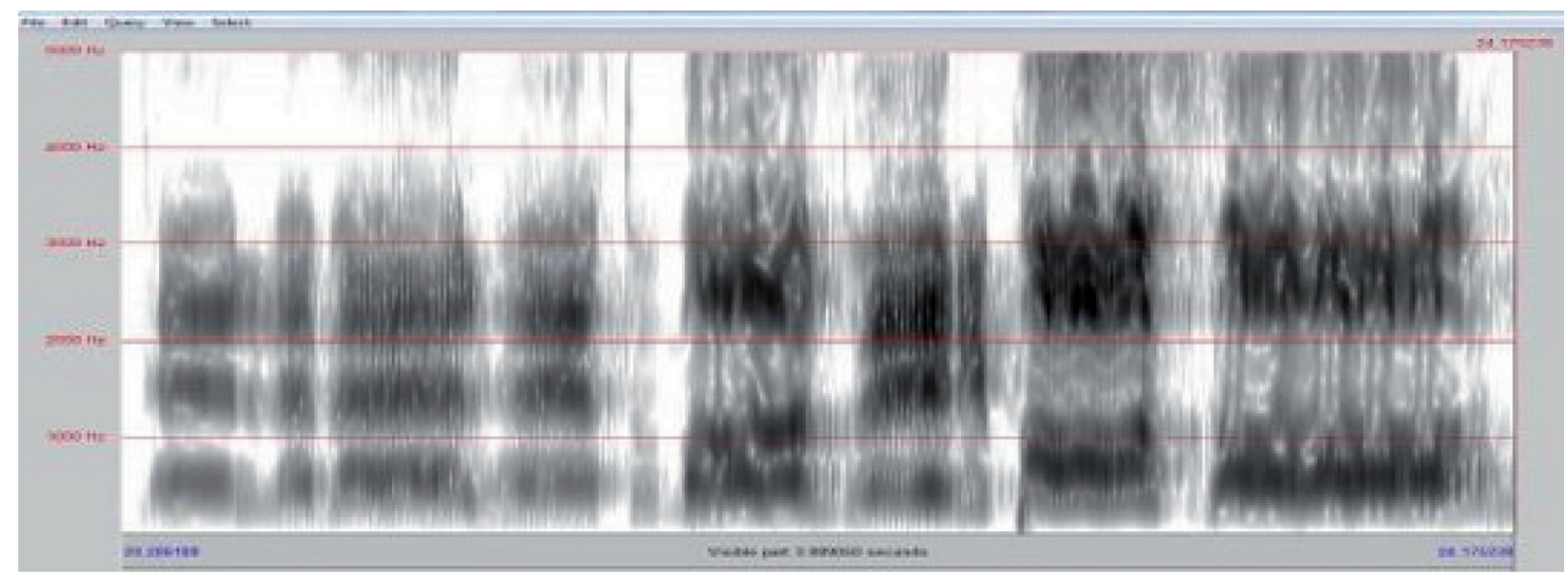

Figura 8: Barítono 7 - Espectografia de banda larga. Fonte: Análise acústica retirada do Programa Praat. 


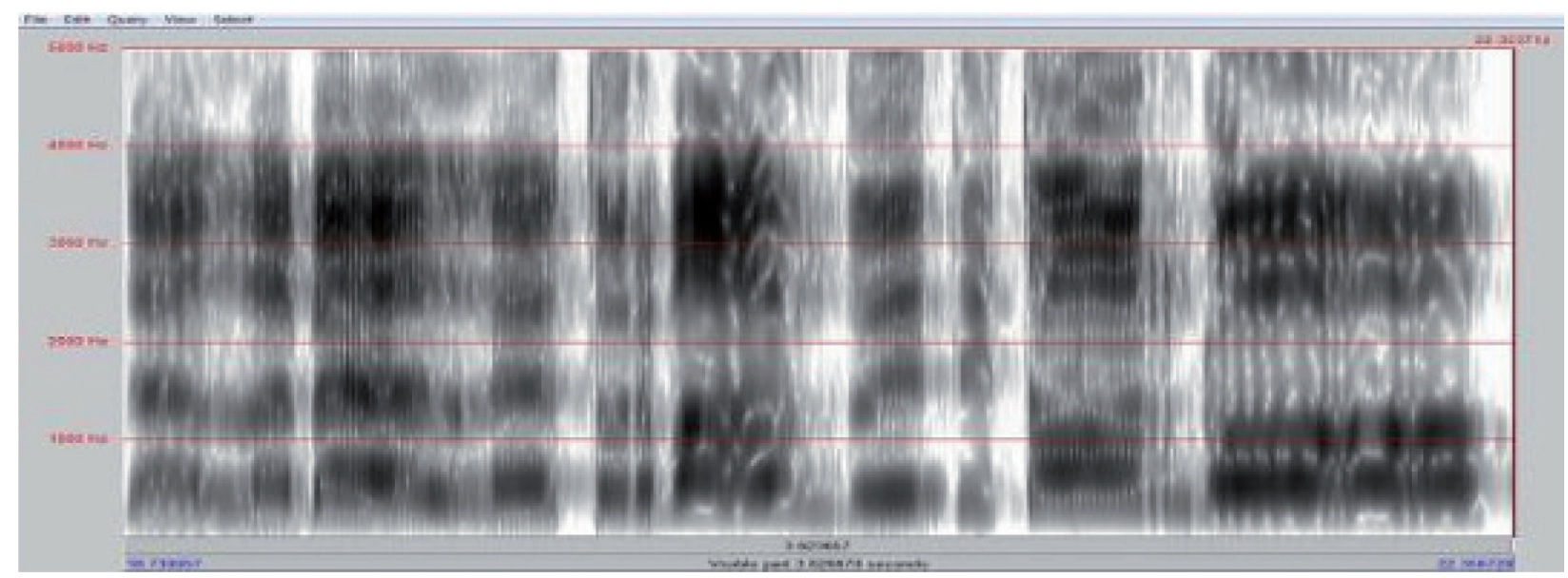

Figura 9: Barítono 8 - Espectografia de banda larga. Fonte: Análise acústica retirada do Programa Praat.

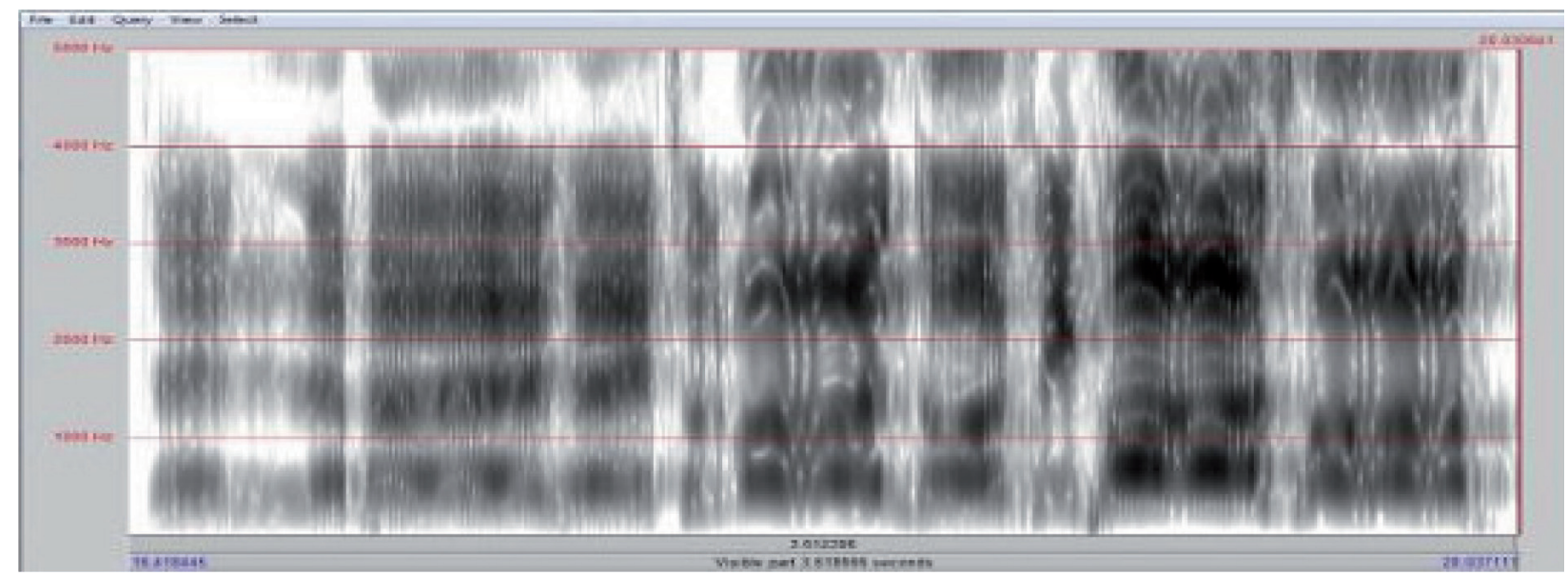

Figura 10: Barítono 9 - Espectografia de banda larga. Fonte: Análise acústica retirada do Programa Praat.

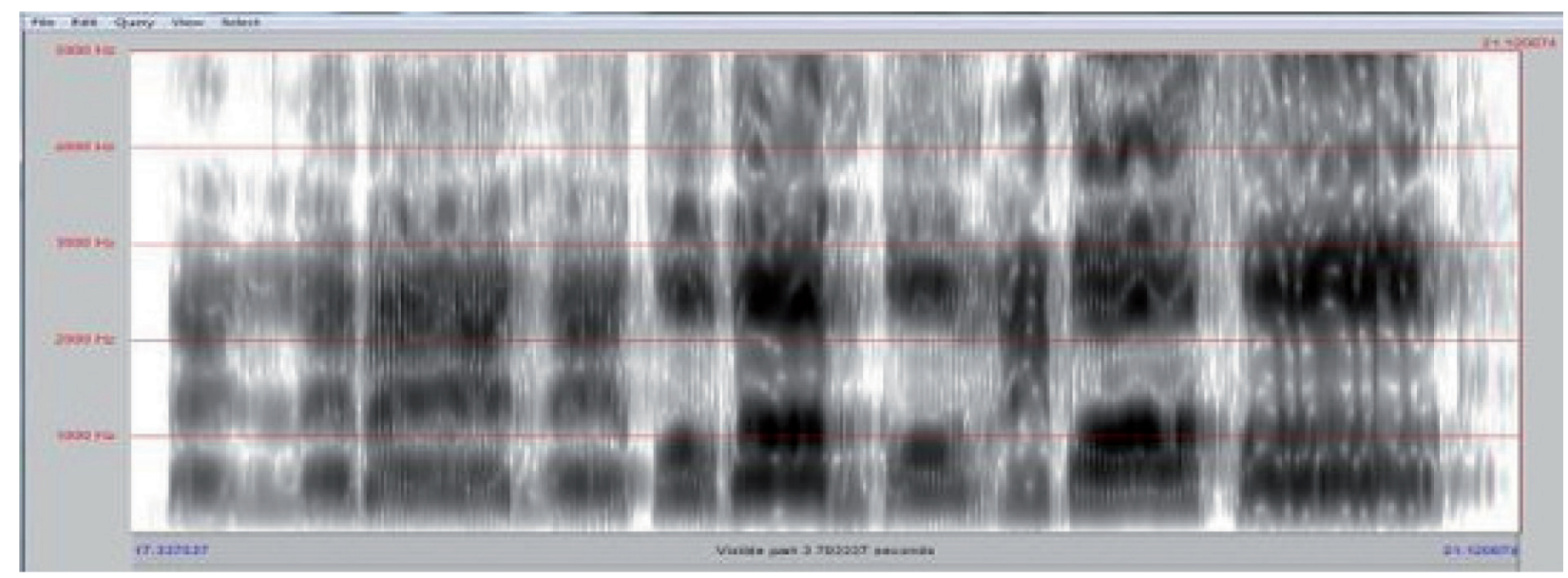

Figura 11: Barítono 10 - Espectografia de banda larga. Fonte: Análise acústica retirada do Programa Praat. 


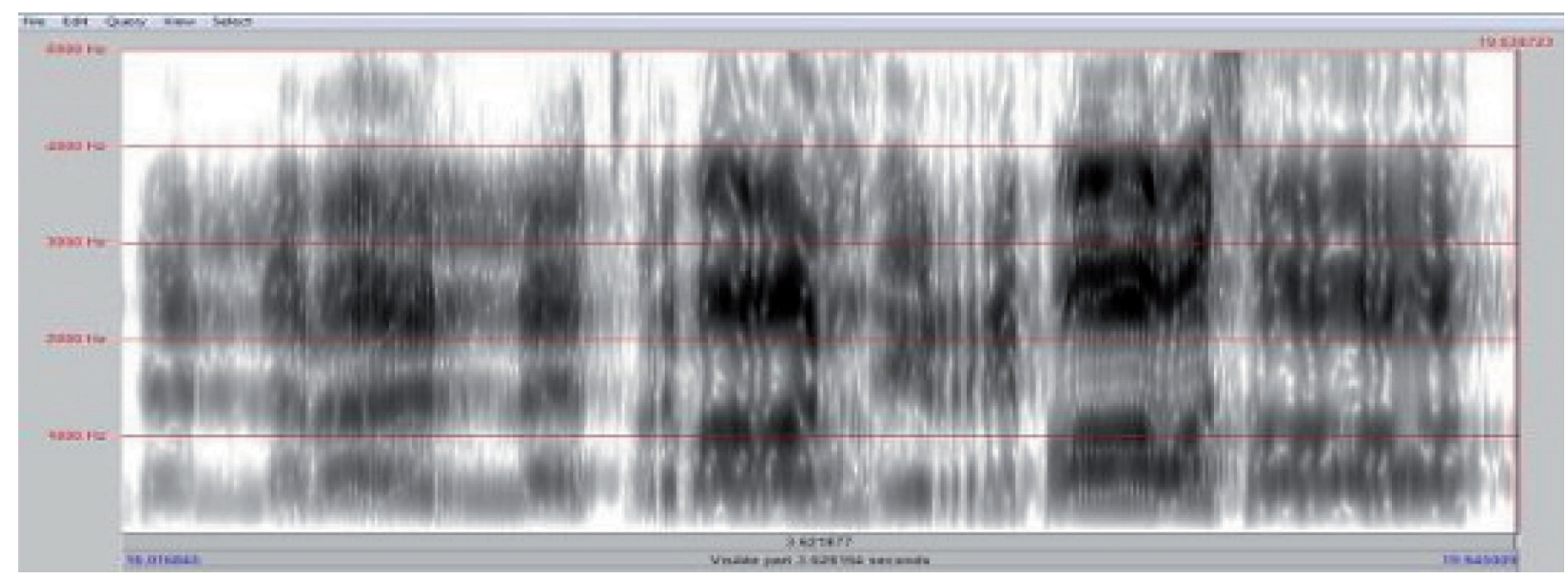

Figura 12: Barítono 11 - Espectografia de banda larga. Fonte: Análise acústica retirada do Programa Praat.

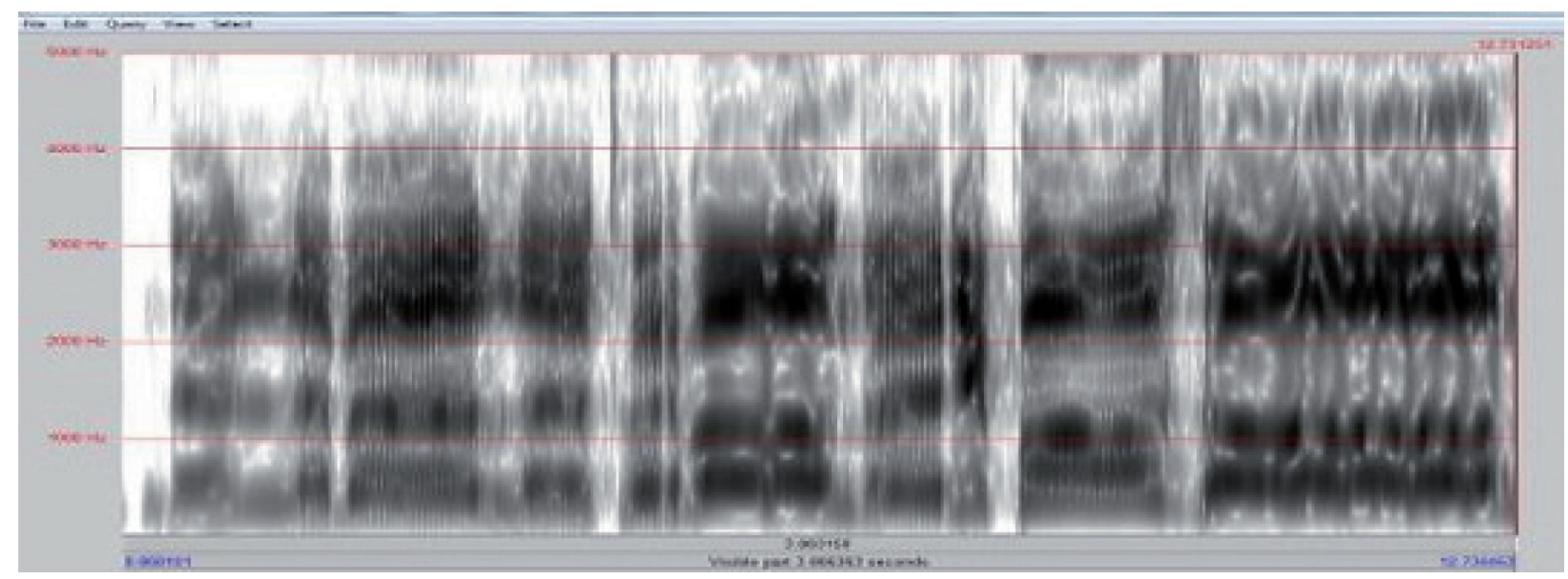

Figura 13: Barítono 12: Espectografia de banda larga. Fonte: Análise acústica retirada do Programa Praat.

Na análise feita pelo programa de análise acústica Praat, foi possível identificar que 100\% dos doze (12) barítonos avaliados apresentaram o Formante do Cantor durante o trecho analisado.

Na análise acústica foi também possível identificar que as frequências que tiveram maior concentração de energia sonora ficaram, em média, na região de $3.500 \mathrm{~Hz}$. Essa região caracteriza o Formante do Cantor, que foi identificado nos espectrogramas de todos os barítonos avaliados.

As frequências do primeiro, segundo, terceiro e quarto formantes podem ser visualizadas no Gráfico 1.

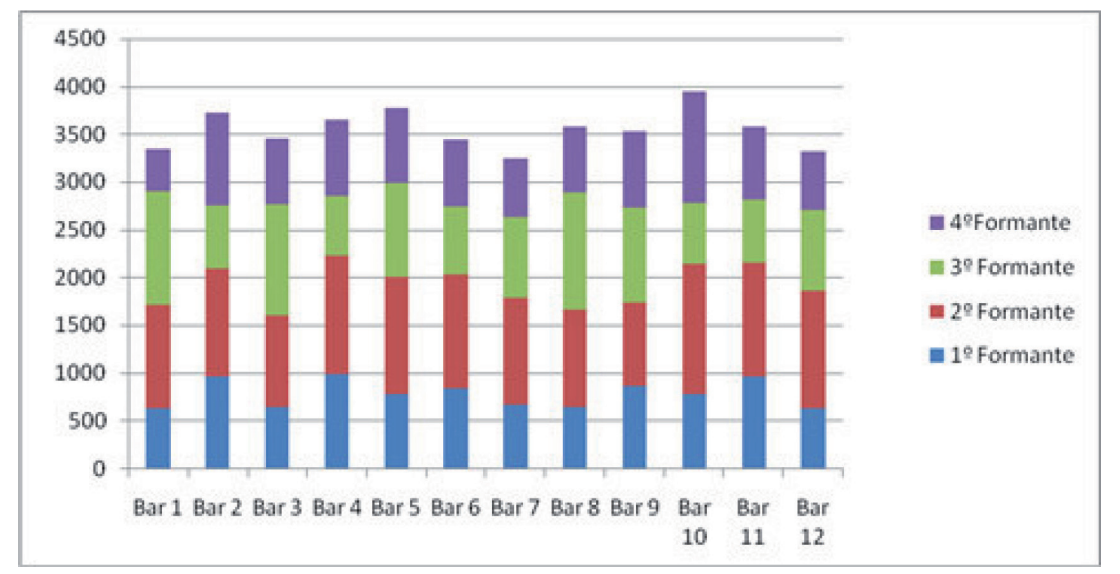

Gráfico 1: frequências do primeiro, segundo, terceiro e quarto formantes. 
É possível identificar pelo Gráfico 1 que a menor frequência de F4 encontrada no trecho avaliado foi de $3252 \mathrm{~Hz}$ e a maior $3944 \mathrm{~Hz}$.

Esses dados ratificam os achados da literatura que relatam que o Formante do Cantor ocorre ao redor dos $3000 \mathrm{~Hz}$ (SUNDBERG, 1991, 2015; CORDEIRO, PINHO e CAMARGO, 2007). É importante ressaltar que o BAR. 10 foi quem teve a maior frequência encontrada, com uma diferença de quase $400 \mathrm{~Hz}$ em relação aos demais barítonos.

Por meio da Fibronasolaringoscopia, foi possível observar que 100\% dos cantores (12) apresentaram o abaixamento da laringe como um dos ajustes para o Formante do Cantor. Essa informação concorda com os achados de (SUNDBERG, 1987, 1991, 2014, 2015; BEHLAU, 2001; CRUZ, 2006; e ANRADE e SILVA E DUPRAT, 2010).

Ainda na laringe, avaliamos a constrição ariepiglótica, ou seja, a aproximação das cartilagens aritenoideas com a epiglote, e encontramos esse ajuste em 7 (58,33\%) dos 12 barítonos avaliados. Essa informação também concorda com o relato de Behlau (2001), que afirma que essa constrição ajuda na ressonância da voz e na amplificação do som produzido. Tanto o abaixamento de laringe quanto a constrição ariepiglótica podem ser visualizados na Figura 14.
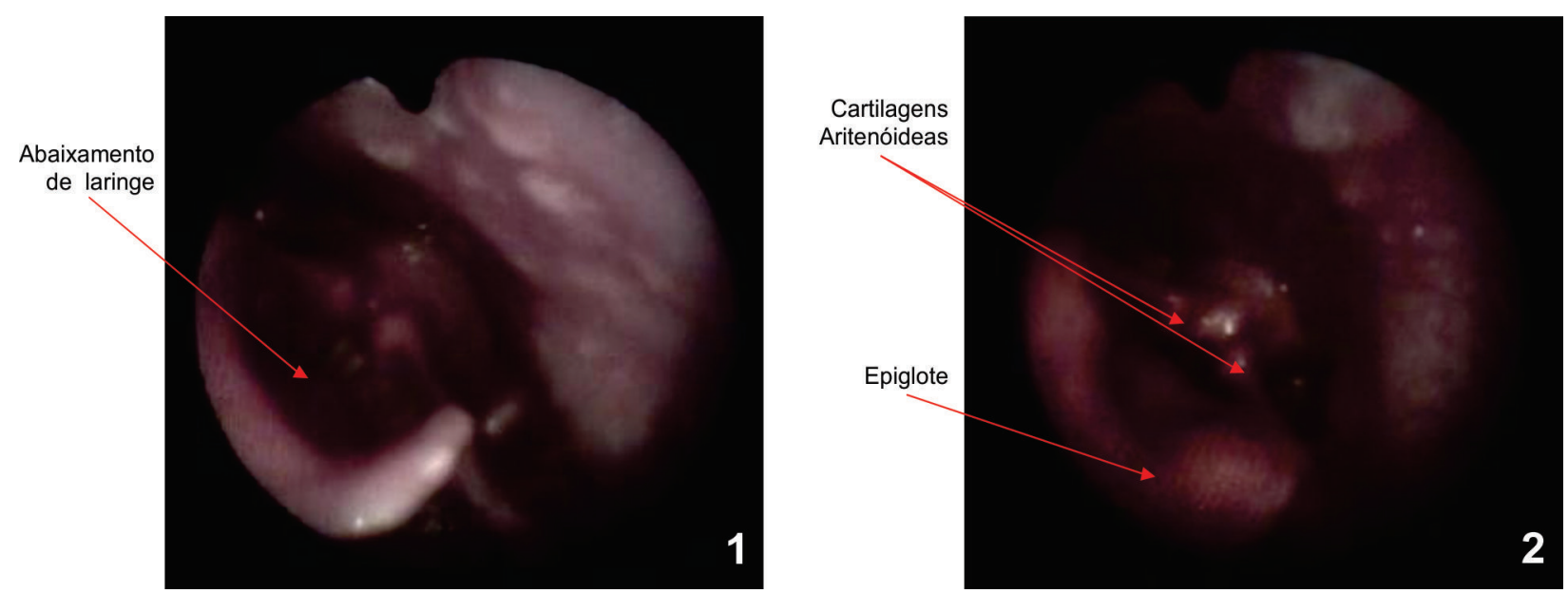

Figura 14: Imagem do exame de Fibronasolaringoscopia. Imagem 1 abaixamento da laringe com alargamento da faringe. Imagem 2 constrição Ariepiglótica. Fonte: Foto da pesquisa.

Outro ajuste que nos chamou atenção foi a posição da língua durante o canto. Verificamos que 4 (33,33\%) dos 12 barítonos avaliados apresentaram posteriorização da base da língua enquanto cantavam. Desses barítonos, 1 (um) apresentou uma alteração estrutural da base da língua, ou seja, uma disfunção denominada macroglossia (aumento da base da língua). Os outros três (3) barítonos apresentaram a posteriorização da língua talvez por uma questão técnica do canto.

A posteriorização da base da língua dos 4 (quatro) barítonos não impediu a visualização da laringe durante a emissão cantada, exceto em um (1) deles, cuja posteriorização dificultou a visualização e a movimentação da laringe devido a grande projeção da base da língua para trás. As estruturas que puderam ser visualizadas durante a emissão cantada desse barítono (BAR. 10) foram a base da língua e as cartilagens aritenóideas, como pode ser visto na Figura 15. 


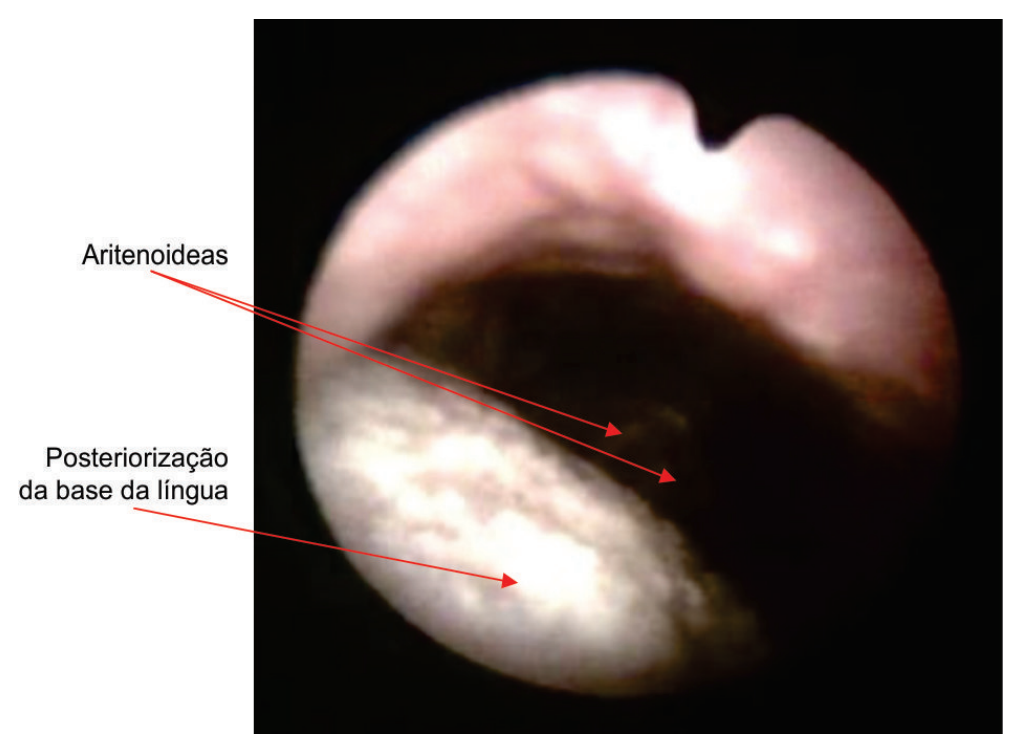

Figura 15: Base da língua posteriorizada durante o trecho avaliado.

Fonte: Foto da pesquisa.

Na faringe foi possível identificar que 9 (75\%) barítonos apresentaram alargamento da faringe durante o trecho avaliado. Esse achado concorda com o trabalho de Sundberg (1987, 1991, 2015), quando o autor relata que a faringe larga é um dos fatores que também favorece o Formante do Cantor. Contudo, 3 (25\%) dos cantores apresentaram constrição lateral durante o canto no trecho avaliado (Figura 16), sendo que dois (2) desses (BAR. 7 e BAR 12) tiveram uma associação de dois ajustes, a constrição lateral da faringe juntamente com a posteriorização da base da língua.

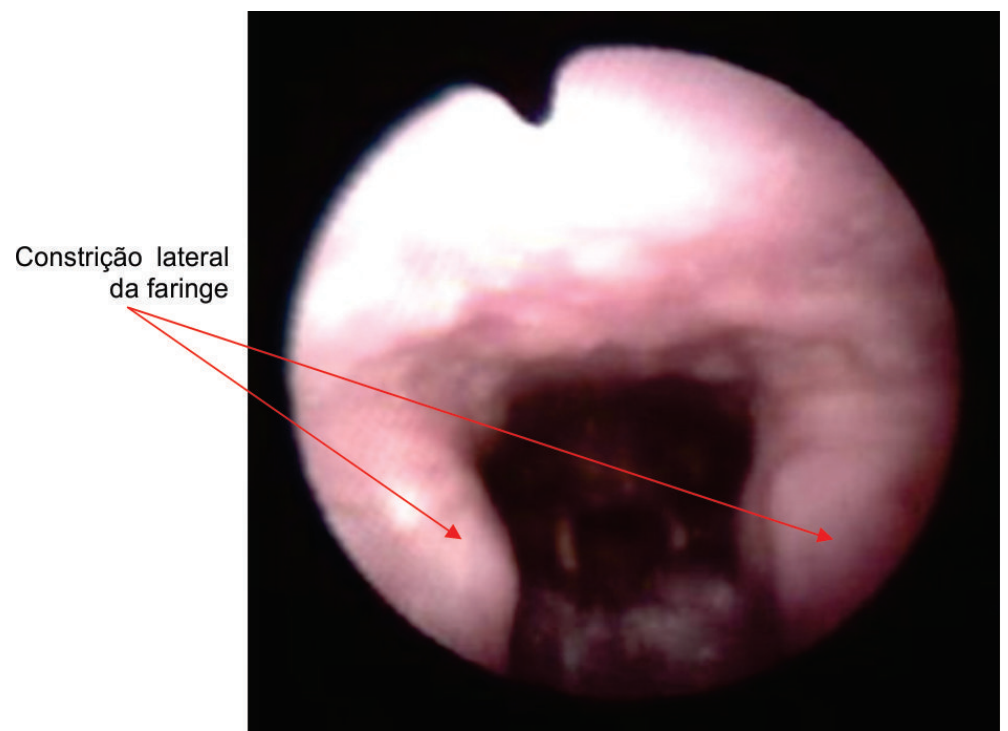

Figura 16: Ajustes da Faringe - costrição lateral da parede da faringe, associado a posteriorização de base de língua. Fonte: Fotos da pesquisa.

Apresentamos, na tabela abaixo, o resumo dos ajustes encontrados e a porcentagem das incidências:

Tabela 1: resumo dos ajuste laríngeos e supralaríngeos encontrados e suas incidências.

\begin{tabular}{|l|c|}
\hline \multicolumn{1}{|c|}{ Ajuste } & Incidência \\
\hline abaixamento da laringe & $100 \%$ \\
\hline constrição ariepiglótica & $58,33 \%$ \\
\hline alargamento da faringe & $75 \%$ \\
\hline constrição lateral da faringe & $25 \%$ \\
\hline posteriorização da base da língua & $33,33 \%$ \\
\hline associação de constrição lateral da faringe com posteriorização da base da língua. & $16,67 \%$ \\
\hline
\end{tabular}




\section{Discussão}

Os dados encontrados na análise acústica mostraram que todos os cantores pesquisados (100\%) apresentaram o Formante do Cantor no trecho avaliado. Esse dado confirma o que a literatura relata: que esse fenômeno é encontrado em vozes de cantores treinados, principalmente do canto erudito (SUNDBERG, 1987, 1991, 2012, 2015; BEHLAU, 2001; CORDEIRO, PINHO e CAMARGO, 2007 e BJORKNER, 2008).

No que se refere aos ajustes laríngeos e supralaríngeos encontrados nesta pesquisa, podemos afirmar que o abaixamento de laringe foi o ajuste laríngeo que mais ocorreu entre os cantores. Esse dado também concorda com os trabalhos de SUNDBERG (1974, 1977, 1987, 1991, 2012, 2015); BEHLAU (2001), CRUZ (2006) e ANDRADE e SILVA E DUPRAT (2010).

Outro ajuste considerado importante na intensificação da ressonância foi a constrição ariepiglótica. Quando esse ajuste ocorre com um abaixamento de laringe e alargamento de faringe, podemos considerá-lo como ideal (SUNDBERG, 1987, 1991 e 2015 e BEHLAU. 2001).

Entretanto, um ajuste que ocorreu em 4 dos 12 barítonos avaliados foi a posteriorização da base da língua, ajuste que não é comentado na literatura científica como favorecedor do aparecimento do Formante do Cantor. Tal ajuste favorece o abaixamento da laringe, já que o osso hioide é a base firme para os movimentos da língua (DAGELO e FANTINI, 2002). Normalmente, nesse ajuste, a musculatura infra-hióidea é mantida em tensão para manter a laringe abaixada e, se o abaixamento for excessivo, ele pode muitas vezes dificultar a movimentação da laringe durante as mudanças de frequências ocorridas no canto.

Um (1) dos barítonos (BAR. 12) apresentou a posteriorização da língua devido a uma alteração estrutural da base da língua e apresentou a segunda menor frequência do Formante do Cantor encontrada nesta pesquisa $(3326 \mathrm{~Hz})$. O fato da base da língua ter sido posteriorizada nos outros três (3) barítonos nos leva à hipótese de que isso pode ter ocorrido devido a uma questão técnica no canto, pois nenhum deles apresentou alteração estrutural que justificasse tal ajuste.

As frequências encontradas na análise acústica dos três barítonos que apresentaram posteriorização da base da língua, mas sem alteração estrutural, foram $3252 \mathrm{~Hz}$ (BAR. 7), 3579Hz (BAR.11) e 3944Hz (BAR. 10). O barítono 7 foi quem apresentou a menor frequência encontrada dentre todos os doze barítonos. O barítono 11 obteve frequência dentro da média encontrada nesta pesquisa. O barítono que apresentou a maior posteriorização da base da língua, dificultando tanto a visualização quanto a movimentação da laringe durante o canto (BAR. 10) foi o cantor que apresentou a maior frequência encontrada, fato que nos chamou bastante atenção.

É de se esperar que emissões vocais com posteriorização de língua levem a resultados sonoros caracterizados pela emissão tensa, sons mais guturais, posteriores, com abafamento de harmônicos e sem projeção ao meio externo. Realmente, um dos barítonos apresentou as frequências mais baixas. Entretanto, outro apresentou frequências medianas e o terceiro barítono apresentou frequências excepcionalmente altas, apesar de ter apresentado a maior posteriorização da base da língua. Esse barítono, provavelmente, realizou outros ajustes laríngeos para conseguir tal resultado, o que merece futuras investigações.

Não podemos deixar de mencionar que o barítono 10 foi o único dos participantes da pesquisa de etnia afrodescendente. Boshoff (1945 apud Pimenta e Pinho, 2001, p. 89) acredita que uma loudness ${ }^{1}$ sonora aumentada é característica de indivíduos afrodescendentes, podendo estar vinculada à maior adução das pregas vocais, já que estes apresentam 
«musculatura laríngea mais vigorosa e mais larga, com inserções musculares de forma mais complexas, cartilagem tireóidea mais flexível, propiciando, possivelmente a maior adução glótica». Além disso, Boshoff observou a inexistência do músculo ariepiglótico (responsável pela composição do esfíncter ariepiglótico). Essa ausência é associada a algumas características musculares, como exemplo, os músculos cricoaritenoideos posteriores, aritenoideos obliquos e transverso serem mais largos.

Mas o que pode justificar uma posição da base da língua tão posteriorizada durante o canto resultar na maior frequência de formantes encontrada nesta pesquisa, com diferença de $400 \mathrm{~Hz}$ em relação aos demais barítonos?

Um questionamento que deve ser pesquisado em populações de indivíduos negros é sobre a inexistência do músculo ariepiglotico. Será que essa ausência pode interferir no Formante do Cantor? E será que o fato dos músculos cricoaritenoideos posteriores, aritenoideos obliquos e transverso serem mais largos já não proporcionam uma compensação para a inexistência do músculo ariepiglotico, facilitando a firmeza laríngea?

Acreditamos que pesquisas futuras comparando etnias distintas talvez respondam a essa questão.

Em relação aos ajustes da faringe, foi possível verificar que 9 (nove) dos cantores pesquisados apresentaram alargamento da faringe, ajuste esse considerado como ideal para o Formante do Cantor (SUNDBERG, 1987, 1991 e 2014), e 3 (três) cantores apresentaram constrição lateral da faringe. Dos três cantores, dois cantores que tiveram constrição lateral da faringe também apresentaram posteriorização da base da língua. Os barítonos que tiveram essa associação de ajustes foram os que apresentaram as menores frequências de harmônicos encontradas na análise acústica. Esses ajustes, entretanto, não impediram que houvesse o Formante do Cantor. Suponha-se que esses ajustes tenham ocorrido por questões relativas à técnica vocal desses cantores e/ou devido a compensações realizadas na base da língua.

Na pedagogia vocal, ajustes laríngeos e supralaríngeos normalmente são explicados de maneira metafórica pelo professor de canto. Algumas imagens mentais que utilizamos usualmente são, por exemplo, a sensação de surpresa ao encontrar alguém que nos é caro, ou a posição de um início de bocejo. Normalmente, ao se imaginar tais posturas, ocorre a elevação do véu palatino, o alargamento da faringe e o abaixamento da laringe, sendo que esse último pode ser percebido de forma tátil ao se colocar os dedos indicador e polegar na altura da cartilagem tireóidea. Ainda, o alargamento de faringe pode ser explicado no contexto da pedagogia do canto metaforicamente como «abrir a garganta». Esse gesto vocal faz com que o aluno entenda que o alargamento do tubo laringofaríngeo é importante para a produção de uma voz com mais harmônicos.

Um som produzido sem tensão, com ajustes laríngeos e faríngeos como o abaixamento de laringe e o alargamento de faringe, resultante da harmonia entre os articuladores, proporciona um trato vocal amplo, favorecendo maior produção de harmônicos e, consequentemente, formantes mais bem definidos e com presença dos formantes superiores com frequências mais agudas (F3, F4 e F5), aqueles que caracterizam o Formante do Cantor (APPLEMAN, 1986).

Os ajustes laríngeos e supralaríngeos encontrados aqui devem ser levados em conta quando se trata de voz cantada, especificamente no canto lírico. Ajustes ou modelos vocais técnicos inadequados que prejudiquem o funcionamento ideal da laringe devem ser revistos, já que um dos grandes objetivos dos cantores é manter uma laringe saudável e longeva. 


\section{Nota}

1 Loudness pode ser descrito como a quantidade de pressão de som sofrida pela membrana timpânica, que resulta na percepção da intensidade da fonte.

\section{Considerações finais}

Este trabalho procurou elucidar questões acerca dos ajustes laríngeos e supralaríngeos utilizados por cantores classificados como barítonos durante a execução de uma ária de ópera. Num primeiro momento, verificou-se que todos os cantores avaliados apresentaram o Formante do Cantor.

Podemos afirmar aqui que os ajustes encontrados nesta pesquisa estão de acordo com os achados literários. Todavia, alguns ajustes, como a posteriorização da base da língua e a constrição lateral da faringe, ajustes não incluídos na literatura como ideais para o Formante do Cantor, podem ter ocorrido por falta de orientação pedagógica no canto ou por uma compensação vocal na produção da voz cantada.

Ressaltamos aqui que o Formante do Cantor é um fenômeno relevante no contexto do canto lírico, quando o cantor tem como pretensão fazer com que sua voz ganhe projeção sobre uma orquestra. Mais importante que isso, entretanto, é a integridade do aparelho vocal durante o canto. Por isso, ajustes técnicos que causem tensão ou desfavorecem a voz do cantor devem ser repensados, pois a longevidade e a saúde da voz são essenciais para o profissional da voz cantada.

Além disso, pesquisas sobre o formante do cantor em diferentes etnias talvez possam apresentar resultados interessantes sobre a voz dos cantores afrodescendentes no contexto operístico e, principalmente, contribuir para com o conhecimento sobre o FORMANTE DO CANTOR.

\section{Referências}

ANDRADE E SILVA M. A. de; DUPRAT, André. Voz cantada. In: FERNANDES, Fernanda D. M.; MENDES, Beatriz C. A; NAVAS, Ana Luiza P. G. P. Tratado de Fonoaudiologia. 2. ed. São Paulo: Editora ROCA, 2010.

APPLEMAN, R. The Science of Vocal Pedagogy. Indiana: Indiana University Press, 1986.

BEHLAU, Mara, AZEVEDO, Renata; MADAZIO Glaucya. Anatomia da laringe e fisiologia da produção vocal. In: BEHLAU, Mara. Voz o livro do especialista. v. 1. Rio de Janeiro: Revinter, 2001. Capítulo 1.

BEHLAU, Mara, MADAZIO, Glaucya, FEIJO, Deborah, PONTES, Paulo. Avaliação de Voz. In: BEHLAU, Mara. Voz o livro do especialista. v. 1. Rio de Janeiro: Revinter, 2001. Capítulo 3.

BELE I.V. The speaker's formant. Journal of Voice. 20(4), 2006. p. 555-78.

BOSHOFF, P. H. The Anatomy of the South African Negro larynx. South African Journal of Medical Sciences, 10: 113-119, 1945 apud PIMENTA, J; PINHO, Sílvia M. R. A voz do Negro In:. PINHO, Sílvia M. Rebelo (Org.). Tópicos em Voz. Rio de Janeiro: Editora Guanabara, 2001.

BJORKNER, Eva. Musical theater and opera singing - why so different: a study of subglottal pressure, voice source, and formante frequency characteristics. Journal of Voice, v. 22, n. 5, p. 533-540, 2008. 
CLEVELAND, Thomas F.; SUNDBERG, Johan.; STONE,R.E (Ed). Long-Term-Average Spectrum chacarteristics of country singers during speaking and singing. Journal of voice, v. 15, n. 1, 2001. p. 54-60.

CORDEIRO, Gislaine Ferro; PINHO, Sílvia M. R; CAMARGO, Zuleica Antonia. Formante do cantor - um enfoque fisiológico. In: PINHO, Silvia M R. Temas em voz profissional. São Paulo: Revinter, 2007. p. 23-30.

CRUZ, Thiago L. B. Estudo dos Ajustes laríngeos e supralaríngeos no canto dos contratenores: Dados Fibronasolaringoscópicos, Vídeo-Radioscópicos, Eletroglotográficos e Acústicos. Belo Horizonte: Escola de Música da Universidade Federal de Minas Gerais, 2006. Dissertação de mestrado.

DANGELO, José G; FANTINI, Carlo A. Anatomia Humana sistêmica e segmentar. 2. ed. São Paulo: Editora Atheneu, 2002.

DONG, Li; SUNDBERG, Johan; KONG, Jiangping. Loudness and Pitch of Kunqu Opera. Journal of voice, v. 28. n. 1, 2014.

FERGUSON S, KENNY DT, CABRERA D. Effects of training on time-varying spectral energy and sound pressure level in nine male classical singers. Journal of Voice. 24(1), 2010. p. 39-46.

LEINO T, LAUKKANEN AM, RADOLF V. Formation of the actor's/speaker's formant: A study applying spectrum analysis and computer modeling. Jounal of Voice, 25(2), 2010. p. 150-8.

MASTER S, BIASE ND, CHIARI BM, PEDROSA V. O espectro médio de longo termo na pesquisa e na clínica fonoaudiológica. Pró-Fono Revista de Atualização Científica, 18(1), 2006. p. 111-20,

MOZART, Wolfgang Amadeus. The Marriage of Figaro (Le Nozze di Figaro): Vocal Score. Ed. Ruth Martin. New York, Schirmer, 1986.

REID, Katherine LP; DAVIS, Pamela; OATES, Jennifer, et al. The acoustic characteristics of professional opera singers performing in chorus versus solo mode. Journal of voice, v. 21, n. 1, 2007.

STEVENS, K.N; HOUSE, A. S. An acoustical theory of vowel production and some of its implications. Journal of Speech and Hearing Research. v. 4, 303-320, 1961.

STONE, R.E (Ed) Jr.; CLEVELAND, Thomas F.; SUNDBERG, Johan. Formant frequencies in country singer's speech and singing. Journal of voice, v. 13, n. 2, 1999. p. 161-167.

SUNDBERG J. Articulatory interpretation of the singing formant. Journal of the Acoustical. Society of Americana, 55, 1974. p. 838-844.

. The Acoustics of the singing voice. Scientific American Offprints. Volume 236, March. Edição 3. Editora W.H Freeman, 1977

. The science of the singing voice. Dekalb, llllinois: North III. Univ. Press, 1987.

. Vocal Tract Ressonance. In: Sataloff RT. Eds. Professional voice: The science and Art of clinical care. New York: Raven Press Ltd.; 1991. p. 49-68.

SUNDBERG J, GRAMMING P, LOVETRI J. Comparisons of pharynx, source, formantand pressure characteristics in operatic and musical theatre singing. Journal of Voice, 6(4), 1993. p. 301-10.

SUNDBERG, J.; GU, Lide.; HUANG, Qiang, HUANG, Ping. Acoustical study of classical Peking opera singing. Journal of voice, v. 26, n. 2, 2012. p. 137-143. 
SUNDBERG, J. A ciência da Voz: Fatos sobre a voz na fala e no Canto. Tradução e revisão, Glaucia Laís Salomão. São Paulo: Editora da Universidade de São Paulo, 2015.

TITZE, Ingo R. Principles of voice production. Estados Unidos: Prentice-Hall, 1994.

. A short tutorial on sound level and loudness for voice. Journal of Singing, v. 70, n. 2, 2013. p. 191-192.

VIEIRA, Maurílio N. Uma introdução à acústica da voz cantada. In: I Seminário Música, Ciência e Tecnologia. São Paulo: AcMUS - I Seminário Música, Ciência e Tecnologia, v. 1, 2004. p. 70-79.

Cristina de Souza Gusmão - Graduada em Fonoaudiologia, Especialista em Voz pelo conselho Federal de Fonoaudiologia, Graduada em Música - Canto, pela Universidade do Estado de Minas Gerias, Mestre em Música pela Universidade Federal de Minas Gerais. Foi professora do curso de Especialização em Voz da FONO-Hosp, BH. Cantora e professora de canto, preparadora vocal e Vocal coaching.

Mônica Pedrosa de Pádua - Graduada em Canto pela Escola de Música da UFMG, Mestre em Música pela Manhattan School of Music (EUA), Doutora em Literatura Comparada pela FALEUFMG. Professora adjunta da EMUFMG, atua no mestrado e doutorado nas áreas de performance e sonologia. Pesquisadora do CNPq, integra o grupo de pesquisa Resgate da Canção brasileira. Solista em concertos e recitalista.

Mariana Oliveira Maia - Graduada em Medicina pela Universidade Federal de Minas Gerais (UFMG) e residência Médica em Otorrinolaringologia pelo Hospital das Clínicas de Minas Gerais /UFMG. Atualmente trabalha como médica otorrinolaringologista no Hospital Felício Rocho e na Clinica de Otorrinolaringologia e Fonoaudiologia Amélio Maia, ambos na cidade de Belo Horizonte - MG. Atua em diversas áreas da Otorrinolaringologia e inclusive com voz falada e cantada. 